\title{
Critical analysis of diagnostic criteria (ICHD-3 beta) about migraine in childhood and adolescence
}

\author{
Análise crítica dos critérios diagnósticos (CIC-3 beta) de enxaqueca em crianças e adolescentes \\ Márcia Maria Ferreira Lima1, Rodrigo Bazan', Luis Cuadrado Martin², Antônio Sérgio Martins³, Gustavo José \\ Luvizutto', Luiz Eduardo Gomes Garcia Betting'1, Marco Antônio Zanini1
}

\begin{abstract}
Objective: The objective of this study was to prospectively evaluate the International Classification of Headache Disorders I (ICHD-I) diagnostic criteria for migraine in children and adolescents. Methods: 150 pain diaries were analyzed during an initial consultation. The duration of migraine headache attacks were divided into 2 groups: Group I, for attacks lasting $>2$ hours, and Group II, for attacks lasting < 2 hours.The two groups were statistically compared using Fisher's exact test ( $<$ 0.05). Results: In this study, 51(34\%) subjects were male and $99(66 \%)$ were female, aged 7-15 years. Fisher's exact test demonstrated that the ICHD-3 beta had a 58\% sensitivity for Group I diagnoses and a $94 \%$ sensitivity for Group II diagnoses ( $p$ < 0.001). Conclusion: The current ICHD-3 beta classification improves and advances migraine diagnosis in children and adolescents; however, more research is needed to identify additional characteristics of headache in this age group.
\end{abstract}

Keywords: headache, diagnostic criteria, childhood, adolescence.

RESUMO

Objetivo: O objetivo deste estudo foi avaliar prospectivamente os critérios diagnósticos da Classificação Internacional das Cefaleias 3 beta (CIC-3) de enxaqueca em crianças e adolescentes. Métodos: 150 diários de dor foram analisados durante a consulta inicial. A duração dos episódios de enxaqueca foram divididos em dois grupos: Grupo I, para episódios com duração > 2 horas, e Grupo II, para os episódios $<2$ horas. Os dois grupos foram comparados estatisticamente pelo teste exato de Fisher $(p<0,05)$. Resultados: Neste estudo, 51 (34\%) pacientes eram do sexo masculino e 99 (66\%) eram do sexo feminino, com idade entre 7-15 anos. 0 teste exato de Fisher demonstrou que a CIC-3 beta teve sensibilidade de 58\% para o diagnóstico do Grupo I e 94\% para o diagnóstico do Grupo II ( $p$ < 0,001). Conclusão: A atual classificação ClC-3 beta melhora e avança diagnóstico de enxaqueca em crianças e adolescentes; no entanto, mais pesquisas são necessárias para identificar as características adicionais de cefaléia nessa faixa etária.

Palavras-chave: cefaléia, critério diagnóstico, infância, adolescência.

Headache is a common problem in childhood. Up to $25 \%$ of children suffer from chronic recurrent headaches. Most headaches are idiopathic in nature; at least $10 \%$ of children between 5 and 15 years of age suffer from migraine. In children and adolescents, headache is a highly prevalent symptom. In a classic study by Bille et al., at least one episode of headache was reported in $40 \%$ of 7 -year-old children and $75 \%$ of 15-year-old adolescents ${ }^{1}$. Several other population studies have shown a prevalence of migraine ranging from $2.7 \%$ to $22 \%{ }^{2,3,4,5,6,7}$. In Brazil, Arruda et al. reported a childhood migraine prevalence of $3.76 \%$ that was non-significantly higher in boys (3.9\%) than in girls (3.6\%), while among children, the probable migraine prevalence was significantly higher than that for all ages (overall prevalence of $17.1 \%)^{8}$. In children and adolescents, tension-type headache and migraine are common. The diagnosis of headaches is typically performed clinically using accurate recollection, but this is very difficult to accomplish in children, especially young children $8,9,10,11,12,13,14$.

Diverse diagnostic criteria for migraine have been used throughout the history of migraine classification ${ }^{1,2,7,13,14,15,16,17}$.

1 Universidade Estadual Paulista, Faculdade de Medicina de Botucatu, Departamento de Neurologia, Psicologia e Psiquiatria, Botucatu SP, Brazil;

Universidade Estadual Paulista, Faculdade de Medicina de Botucatu, Departamento de Clínica Médica, Botucatu SP, Brazil;

${ }^{3}$ Universidade Estadual Paulista, Faculdade de Medicina de Botucatu, Departamento de Cirurgia, Botucatu SP, Brazil.

Correspondence: Gustavo José Luvizutto; Departamento de Neurologia, Psicologia e Psiquiatria, Faculdade de Medicina de Botucatu, UNESP; Av Prof Montenegro, s/nº; Distrito de Rubião Junior, 18618-970 Botucatu SP, Brasil; E-mail: gluvizutto@fmb.unesp.br

All authors contributed equally to the manuscript and participated sufficiently in the work to take public responsibility for appropriate portions of the content. Conflict of interest: There is no conflict of interest to declare.

Received 27 March 2015; Received in final form 17 July 2015; Accepted 05 August 2015. 
Some authors have defined migraine as paroxysmal headaches separated by symptom-free intervals with at least two of the following four features: (1) unilaterality; (2) nausea; (3) visual aurea; (4) family history of migraine ${ }^{1,13}$.

In 1988, the International Headache Society (IHS) proposed a new system for classifying headache-related disorders, the International Classification of Headache Disorders I (ICHD-I), which was based on operational criteria. However, several studies have demonstrated that these criteria have a low sensitivity 9,14,16,18,19. The most cited ICHD-I criteria for migraine without aura in children was a decrease in the minimum duration of crises to one hour, which would increase sensitivity ${ }^{14,16}$.

The criticisms of the ICHD-I criteria at the 1999 IHS committee meeting led to the establishment of a new edition in 2004, the Classification and Diagnostic Criteria for Headaches II (ICHD-II ). Several updates were made, including changing the minimum headache duration to 1 to 72 hours (instead of 4-72); however, a duration of less than 2 hours still required diary corroboration ${ }^{20,21}$. To substantiate this criteria, the IHS conducted a study of pain diaries.

Studies using the ICHD-II 2004 classification can be found in the literature, and most of these studies also noted that the duration of headache in childhood and adolescence is shorter than the duration in adulthood. However, these studies are few, and the majority are retrospective, and therefore biased $^{22,23,24,25,26,27}$. In 2013, the IHS published the beta version of the ICHD-3 and promoted its use $\mathrm{e}^{22,23}$.

Our study hypothesized that a duration criterion of less than two hours corroborated by a diary can be used with good sensitivity to diagnose migraine in children and adolescents. Therefore, the objective of this study was to prospectively evaluate the ICHD -3 beta 2013 diagnostic criteria for migraine in children and adolescents using diaries.

\section{METHODS}

\section{Study design}

This was a prospective cohort study conducted between January 2013 and June 2014, in which one hundred and fifty diaries were analyzed after being used daily by individuals to record their experiences of pain. Several instances were recorded, including untreated episodes, duration of the episodes (i.e., less than 2 hours or more than 2 hours), nausea and/or vomiting, and photophobia, phonophobia or osmophobia. The patients were from the Headache Outpatient Ward for Children and Adolescents, GHMS-UNESP-Botucatu. Adolescents after menarche were also included in this study; therefore, menstrual crises were considered interchangeably.

\section{Procedures}

At the first consultation, patients were instructed on how to fill out the diary and non-prophylactic treatment was established thirty days before the return of the completed diaries. Individuals were classified into two diagnostic groups according to gender, age, type and duration of pain (i.e., more than half of the crises in a month with a duration of more or less than 2 hours) and type of headache, according to the following:

a) ICHD - 3 beta 2013 episodes lasting > 2 hours, diagnosis criteria for migraine Group I;

b) ICHD-3 beta 2013 episodes lasting < 2 hours, diagnosis criteria for migraine Group II.

The ICHD 3 criteria were fully considered for all operational criteria, notes and comments involving children and adolescents, including pain during the period between falling asleep with a headache and waking up without it.

\section{Statistical analysis}

Based on the headache frequencies observed in both groups, we estimated that the power of the test is approximately $70 \%$, assuming for calculation of the effect, simple random sampling and type I error probability $=0.05$. The two groups (GI, GII) were statistically compared using Fisher's exact test $(p<0.05)$. Statistical analyses were performed using SPSS v.15.0 software.

\section{Ethical procedure}

This study may be considered without methodological risk because it only used standard instruments to assess patients and did not intentional use any intervention or modification of physiological, psychological and social variables of individual subjects. The study was approved by the GHMS medical ethics committee at UNESP in Botucatu, Sao Paulo state, Brazil.

\section{RESULTS}

This study initially followed 810 patients, 660 of which were excluded for reasons shown in the flow diagram (Figure 1). Of the remaining subjects, 51 (34\%) were male and $99(66 \%)$ were female, aged $7-15$ years, mean age \pm standard deviation was $8.32 \pm 6.63$. The classical symptoms associated with headache included nausea (65\%), vomiting (52\%), photophobia (96\%), phonophobia (97\%), vertigo (52\%) and osmophobia (54\%). However, the latter did not aid in diagnosis because every patient who had osmophobia also had either photophobia or phonophobia.

The ICHD-3 beta Group I category had 88 subjects, with the majority of crises lasting more than 2 hours, and the ICHD-3 beta Group II category had 62 subjects with majority of crises lasting less than 2 hours.

Of the 150 patients studied, only 88 had migraine lasting more than two hours, thus the sensitivity of the test for detecting migraine lasting longer than two hours was 88/150 or $58 \%$. If we included in the diagnosis those individuals with 
a migraine duration between 1 and 2 hours (54 patients) we found 142 individuals, which results in a sensitivity of $94 \%$, $\mathrm{p}<0.001$. To achieve a sensitivity of $100 \%$, (150/150 patients) we would have to include any headache duration (Figure 2).

The sensitivity of diagnosis among girls ranged from $61 \%$ to $93 \%$, and among boys from $57 \%$ and $98 \%$.

\section{DISCUSSION}

Since their proposal in 1988, the criteria from the International Classification of Headache Disorders have been evaluated for their agreement with clinical diagnosis. Prior to IHS publication of the ICHD, several classifications were used for headache diagnosis in children. For example the criteria established by Vahlquist in 1955, Deubner in

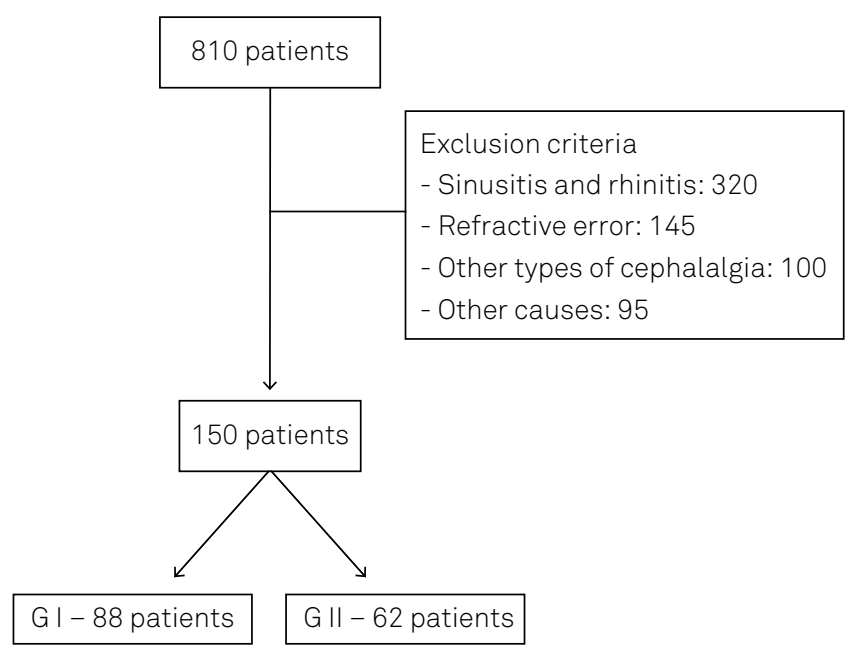

Figure 1. Flow diagram.

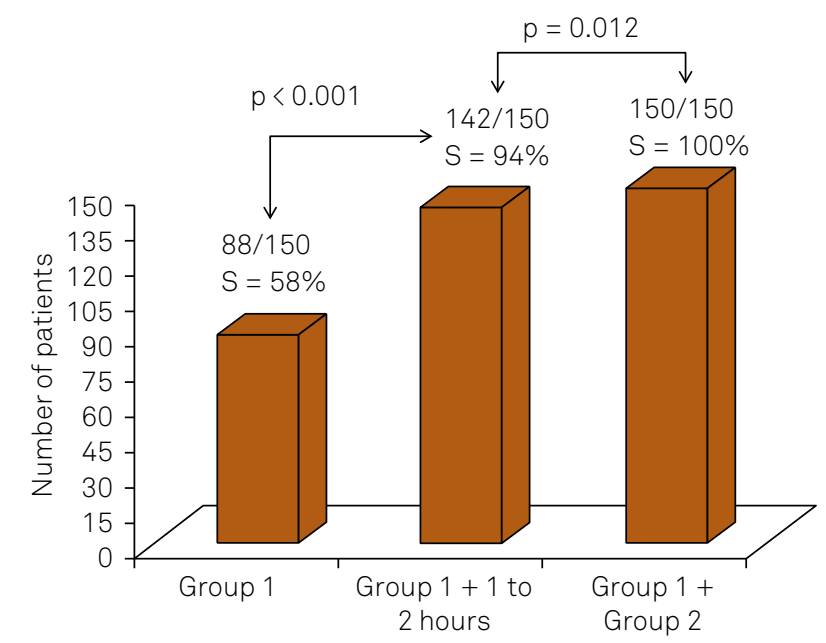

Figure 2. Sensitivity of headache duration in the diagnosis of migraine in childhood. Group 1 includes episode durations greater than 2 hours; group 2 includes episode durations of less than two hours.
1977 and Prensky and Sommer in 19792,4,14. When the criteria from the International Classification of Headache Disorders were evaluated using clinical diagnoses assigned by pediatric neurologists as the gold standard, the criteria were very specific in diagnosing migraine without an aura in children, but the sensitivity was very low (ranging from 27.3-53\%). Additional research suggested that the condition of a 1 hour duration for a migraine attack should be shortened and that hemicrania should be removed as a criterion because many children have headaches that are bitemporal or bifrontal. An additional suggestion was to require either photophobia or phonophobia for diagnosis, but not both ${ }^{24,25,26,27,28}$.

The ICHD-3 beta was created mainly for adult patients. The only specific criterion introduced for children concerns the duration of the migraine attacks, where a duration of 1 to 72 hours (instead of 4-72) is accepted, but a duration of less than 2 hours requires corroboration by a diary. Furthermore, although the ICHD-3 beta states that migraine headache is commonly bilateral in young children, no specific criterion for this aspect has been introduced. The classification also reports that in children, photophobia and phonophobia may be inferred from behavior.

Some authors consider that the intuitive clinical diagnosis given by a specialist, should be the standard diagnosis. This suggestion is prone to criticism because there are no homogeneous standard diagnostic criteria, despite their validity and utilization in several studies.

Pacheva et al. ${ }^{29}$ recommended using "severe intensity" as the only category for migraine intensity. Francis ${ }^{30}$ concluded that if the duration of pain is less than one hour, two additional features should be added to diagnose migraine without an aura, having one parent or sibling with migraine and having one of the migraine triggers precipitating head pain.

Our data from the headache diaries suggests that using a migraine episode duration of less than two hours (Group II) may result in greater sensitivity, as demonstrated by the Fisher's test. The results of the present prospective work, in comparison to our previous retrospective study ${ }^{28}$, showed that the sensitivity of ICHD-3 beta in this study is higher than the sensitivity found in the other study. This finding is probably a result of the present study being prospective, and the first study, despite its conclusions, has limitations from being retrospective, and therefore is biased. This bias was likely the result of the evaluation of the patient chart data, which included the duration of pain that parents and/or caregivers gave during the consultation.

The present study did not have a large population sample, and as a result may also be biased. However the statistically significant results are scaled to the diagnosis in outpatients. Another limitation was the inclusion of adolescents in menarche because menstrual crises were not different from other crises. However, this is more representative of situations in real life. Furthermore, fluctuations of crises were not considered in this study. 
In conclusion, the results clearly show that although ICHD-3 beta diagnosis has a high sensitivity, there are still some limitations. ICHD-3 beta diagnosis of migraine is more sensitive and accurate with a prospective diaries analysis in children compared to a retrospective analysis. In the 25 years that elapsed between the ICHD I and ICHD-3 beta, classification of migraine episodes lasting less than 2 hours were acceptable when associated with information from a diary.

In our opinion the current ICHD-3 beta classification does improve and advance migraine diagnosis in children and adolescents; however, more research is needed on other characteristics of headache to focus on developing criteria in this age group that are distinct from those applicable to adults.

\section{References}

1. Bille B. Migraine in schoolchildren. Acta Paediatr Scand.1962;51(5):1-151. doi:10.1111/j.1651-2227.1962.tb06591.x

2. Vahlquist B. Migraine in children. Int Arch Allergy. 1955;7(4-6):348-55. doi:10.1159/000228238

3. Dalsgaard-Nielsen T, Engberg-Pedersen H, Holm HE. Clinical and statiscal investigation of the epidemiology of migraine. Dan Med Bull. 1970;17(5):138-48.

4. Deubner DC. An epidemiologic study of migraine and headache in 10-20 year olds. Headache. 1977;17(4):173-80. doi:10.1111/j.1526-4610.1977.hed1704173.x

5. Waters WE. Community studies of the prevalence of headache. Headache. 1974;9(4):178-86. doi:10.1111/j.1526-4610.1970.hed0904178.x

6. Sparks JP. The incidence of migraine in school children. Practitioner. 1978;221:407-11.

7. Sillanpää M. Changes in the prevalence of migraine and other headaches during the first seven school years. Headache. 1983;23(1):15-9. doi:10.1111/j.1526-4610.1983.hed2301015.x

8. Arruda MA, Guidetti V, Galli F, Albuquerque RCAP, Bigal M. Primary headaches in childhood-a population-based study. Cephalalgia. 2009;30(9):1056-64. doi:10.1177/0333102409361214

9. Headache Classification Committee of the International Headache Society. Classification and diagnostic criteria for headache disorders, cranial neuralgias and facial pain.Cephalalgia. 1988;8 Suppl 7:1-96.

10. Barlow CF. Headaches and migraines in childhood. Philadelphia: Spastics International Medical; 1984. p. 288. (Clinics Developmental Medicine, vol.91).

11. Hochaday JM, Barlow CF. Headache in children. In: Olesen J, Tfelt-Hansen P, Welch KMA, editors. The headaches. NewYork: Raven Press, 1993. p. 795-808.

12. Aromaa M, Sillanpää M, Rautava P, Helenius H. Childhood headache at school entry: a controlled clinical study. Neurology. 1998;50(6):1729-36. doi:10.1212/WNL.50.6.1729

13. Mortimer MJ, Kay J, Jaron A. Epidemiology of headache and childhood migraine in an urban general practice using AdHoc, Vahlquist and IHS criteria. Dev Med Child Neurol. 1992;34(12):1095-105. doi:10.1111/j.1469-8749.1992.tb11423.x

14. Wöber-Bingol C, Wöber C, Karwautz A, Vesely C, Wagner-Ennsgraber C, Amminger GP et al. Diagnosis of headache in childhood and adolescence: study in 437 patients. Cephalalgia. 1995;15(1):13-21. doi:10.1046/j.1468-2982.1995.1501013.x

15. Congdon PJ, Forsythe WI. Migraine in childhood: a study in 300 children. Dev Med Child Neurol. 1979;21(2):209-16. doi:10.1111/j.1469-8749.1979.tb01603.x

16. Cano A, Palomeras E, Alfonso S, Ortega D, Sanz P, Fossas P. Migraine without aura and migrainous disorder in children; International Headache Society (IHS) and revised HIS criteria. Cephalalgia. 2000;20(7):617-20. doi:10.1111/j.1468-2982.2000.00103.x
17. Ad hoc committee on classification of headache. Classification of Headache.JAMA. 1962;179(9):127-8.

18. Metsähonkala L, Sillanpää M. Migraine in children: an evaluation of the IHS criteria. Cephalalgia. 1994;14(4):285-90. doi:10.1046/j.1468-2982.1994.1404285.x

19. Winner P, Martinez W, Mate L, Bello L. Classification of pediatric migraine proposed revisions to IHS criteria. Headache. 1995;35(7):407-10. doi:10.1111/j.1526-4610.1995.hed3507407.x

20. Wöber $C$, Wöber-Bingöl C. Pediatric migraine and the International Headache Society criteria. Neurology. 1998;50(3):831-2. doi:10.1212/WNL.50.3.831-b

21. Headache Classification Sub-Committee of the International Headache Society. The International Classification of Headache Disorder, $2^{\text {nd }}$ edition. Cephalalgia. 2004;24:1-160.

22. Headache classification Committee of the International Headache Society (IHS) The International Classification of Headache Disorders, $3^{\text {rd }}$ edition (beta version). Cephalalgia. 2013;33(9):629-808.

23. Olesen J. ICHD-3 beta is published. Use t immediately. Cephalalgia. 2013;33(9):627-8. Headache Classification Sub-Committee of the International Headache Society. The International Classification of Headache Disorder, $2^{\text {nd }}$ edn. Cephalalgia. 2004;24:1-160.

24. Abu-Arafeh I, Callaghan M. Short migraine attacks of less than $2 \mathrm{~h}$ duration in children and adolescents. Cephalalgia. 2004;24(5):333-8. doi:10.1111/j.1468-2982.2004.00670.x

25. Hershey AD, Winner P, Kabbouche MA, Gladstein J, Yonker M, Lewis D, Pearlman E et al. Use of the ICHD - II Criteria in the diagnosis of pediatric migraine. Headache. 2005;45(10):1288-97. doi:10.1111/j.1526-4610.2005.00260.x

26. Lima, MM, Padula, NA, Santos LC, Oliveira LD, Agapejev S, Padovani C. Critical Anaysis of the international classification of headache disorders diagnostic criteria (ICHD I-1988) and (ICHD II-2004), for migraine in children and adolescentes. Cephalalgia. 2005;25(11):1042-7. doi:10.1111/j.1468-2982.2005.00954.x

27. Senbil N, Gürer YK, Aydin OF, Rezaki B, Inan L, Inan L.. Diagnostic criteria of pediatric migraine without aura. Turk J Pediatr. 2006;48(1):31-7.

28. Rossi LN, Vajani S, Cortinovis I, Spreafico F, Menegazzo L. Analysis of the International Classification of Headache Disorders for diagnosis of migraine and tension-type headache in children. Dev Med Child Neurol. 2008;50(4):305-10. doi:10.1111/j.1469-8749.2008.02041.x

29. Pacheva I, Milanov I, Ivanov I, Stefanov R. Evaluation of diagnostic and prognostic value of clinical characteristics of migraine and tension type headache included in the diagnostic criteria for children and adolescents in International Classification of Headache Disorders- second edition. Int J Clin Pract. 2012;66(12):1168-77. doi:10.1111/ijcp.12024

30. Francis MV. Brief migraine episodes in children and adolescents- a modification to International Headache Society pediatric migraine (without aura) diagnostic criteria. Springerplus. 2013;2(1):77. doi:10.1186/2193-1801-2-77 